\title{
Health Care Integration and Coordination with Emphasis on Mental Health, but Not for Medical Marijuana
}

\author{
Marjorie A. Bowman, MD, MPA, Dean A. Seebusen, MD, MPH, \\ and Anne Victoria Neale, PhD, $M P H$
}

Care coordination and behavioral health care integration are the subject of 4 of this month's articles. Patients with significant illness report that care coordination provides great challenges to them, and they expect family physicians to assist with the referrals and communication between the doctors. Patients' primary care providers were usually not the prescribers of patients' medical marijuana and were often unaware of its use, indicating lack of health care integration and coordination. Two articles provide insight into medication adherence. Also, how are family physicians addressing patient engagement at the practice level? Clinical topics in this issue include the following: specific exercises were not the answer to restless legs; epidural anesthesia may be associated with fewer, not more, vaginal lacerations; and fecal incontinence is less discussed but not necessarily less problematic than urinary incontinence. On the popular culture front, opioid mentions in top 100 songs are increasing. Lastly, what does it mean for the field of family medicine that some of us choose to become hospitalists? (J Am Board Fam Med 2018;31:667-670.)

\section{Care Coordination and Integration, with an Emphasis on Behavioral Health}

Care coordination feels difficult for many clinicians. However, for the patients and their families, it may be even more challenging. ${ }^{1}$ Patients with multiple providers and/or emergency department visits, or providers in different health care systems often find care coordination quite difficult, and confusing. "It is really overwhelming" is quite descriptive of the experiences some patients report. Interestingly, "superusers" of the emergency department were excluded from this study. Importantly, Chang et $\mathrm{al}^{1}$ report that patients expected their family physicians to undertake the coordination.

Care coordination may be improved through behavioral health integration in primary care practices. Blasi et $\mathrm{al}^{2}$ provide extensive interviews of integrated behavioral health primary care practices and provide excellent details on methods the practices use and their frequency, courtesy of funding from the Robert Wood Johnson Foundation. Table 3 provides specifics on who in the office performs

Conflict of interest: The authors are editors of the $7 A B F M$ which task. For those attempting to integrate behavioral health or seeking to improve what they already do, this article has much to offer.

Many of our current reimbursement mechanisms are not designed to acknowledge or reward care coordination. The Centers for Medicare and Medicaid Services funded a large project called Care of Mental, Physical, and Substance use Syndromes as an intervention for depression, diabetes, and cardiovascular diseases with 3854 patients in 8 health systems. Beck et $\mathrm{al}^{3}$ report that even with this funding, the process of implementation for the care coordination and intervention was lengthier than anticipated and many of the required phone calls and care management tasks were not reimbursed. The final results ${ }^{4}$ were positive but varied widely. Longer involvement in the program provided better results. The authors provide recommendations for future directions.

One of the challenges of behavioral health integration is how to get the needed information into electronic health records to coordinate care across multiple types of providers. In a study funded by the National Institutes of Mental Health, Jetelina 
et $\mathrm{al}^{5}$ report that electronic health record tools were created and planned to be implemented at 6 community health centers, and results were compared with 6 other community health centers. Of note, not all the intervention sites implemented the tools. Patient perceptions were positive. The authors present the mixed outcomes with lessons for next steps. In another article, Hirschtritt et $\mathrm{al}^{6}$ report that implementing one behavioral screening tool did not predict implementation of another; despite high rates of questionnaire screening for the hazardous use of alcohol in one large health system, screening for depression by questionnaire was uncommon, even among those with significant alcohol intake.

In terms of medical marijuana, it is telling, but perhaps not surprising, that family physicians in Colorado were not usually the prescriber of medical marijuana for their patients and often did not even know about patients' use. ${ }^{7}$

Patient engagement in family medicine is most commonly in the form of patient surveys and patient suggestion boxes. ${ }^{8}$ Patient advisory councils or involvement in quality improvement activities were more likely in practices that were larger and patient-centered medical home certified, leaving the question of how many practices would have done this without the push of patient-centered medical home certification and the associated financial incentives. These types of patient engagement are also more likely in federally qualified community health centers and accountable care organizations, where they are required; this could lead a cynic to think that practices do not usually, on their own, believe that practice-level patient engagement is worth the effort. To date, we are still seeking robust evidence that indicates patient engagement leads to improved patient outcomes, although Sharma et $\mathrm{al}^{8}$ report that such a study is currently underway. Why is it that high-level engagement was reported more frequently by female and minority physicians?

\section{Medication Adherence}

Unfortunately, and this is not well known, women are more likely to not adhere to their diabetes medicines due to cost, almost one-third more frequently than men. ${ }^{9}$ We agree with Bhuyan et $\mathrm{al}^{9}$ that the reasons must be explored and measures taken that address the issues specific to women.
Schoenthaler et $\mathrm{al}^{10}$ noted that shared decision making may be more important to medication adherence (as measured by an electronic monitoring device) when the physician-patient relationship is relatively new.

\section{The Top 100 and Opioids: an Epidemic in Music Lyrics}

In one of our more unusual articles, ${ }^{11}$ lyrics in the Billboard's top 100 songs in recent years have increasingly referred to mind-altering substances, including many mentions of prescription opioids. Is this entertainment following trends or possibly worsening current opioid issues through the equivalent of "advertising" and public acceptance? If it would create even a small difference in opioid and drug abuse, I (MAB) suggest some major entertainers create a "not-me too" campaign to get such references out of popular music.

\section{Important Clinical Research and Information}

Based on a study of 2131 vaginal deliveries, Myrick et $\mathrm{al}^{12}$ identified that epidural anesthesia was associated with fewer sutured vaginal lacerations in 2 different safety-net hospitals with different types of providers. However, the suburban hospitals staffed primarily by family medicine residents and faculty had fewer vaginal lacerations, even after controlling for various risk factors, than the urban hospital staffed by obstetrics residency and faculty.

Regarding fecal incontinence, "If we do not ask, they will not tell," does seem particularly pertinent. Brown et $\mathrm{al}^{13}$ found that physicians felt better informed to treat urinary than fecal incontinence. Is it because there so many products, medicines, and medical techniques that help with urinary incontinence and so many ads to market them? This article is a reminder to ask about and offer treatment for fecal incontinence, often concurrent with urinary incontinence.

Restless legs can be quite painful. Just last week I (MAB) had a patient in home hospice, begging for his nonopioid restless leg medication, which apparently had not been provided on his most recent of 4 hospital discharges in 4 months, and after 40 pounds of lost weight, he said "Doc, them legs is worse than all the rest of this!" Given that the medication is the current recommended treatment, Harrison et $\mathrm{al}^{14}$ report a randomized trial of exercise therapy with a comparison discussion group. 
An analysis of the usefulness of magnetic resonance imaging (MRI) of the wrist for actionable abnormalities ${ }^{15}$ is pertinent to the practice of family medicine and provides specific direction as to when to order MRI based on findings and outcomes of 140 MRI scans. In general, wrist MRIs are not very useful for older patients with subacute or chronic pain; see greater detail in the article. If in doubt, referral to the appropriate specialist before ordering an MRI is preferable.

Crawford et $\mathrm{al}^{16}$ report that cinnamon bark powder was associated with leg edema in a patient who later developed congestive heart failure. Another article by Mainous et $\mathrm{al}^{17}$ found that a clinical decision support tool was associated with improved care management for sickle cell disease patients. In a timely review article, Kulkarni and Manek ${ }^{18}$ provide a review of the how to interrupt or reverse the direct oral anticoagulants.

\section{Family Physician Hospitalists}

In 2016, a small minority of family physicians surveyed 3 years after residency graduation identified themselves as hospitalists. They were more likely to be male, work more hours, and were more satisfied. ${ }^{19}$ Per the Association of American Medical Colleges, $17 \%$ of hospitalists were family physicians in $2013 .{ }^{20}$ These rates of family physicians as hospitalists could be considered a negative-we need all the family physicians in an outpatient setting we can get-but it could also be a positive, as the option of becoming a hospitalist may mean the following: (1) more people enter family medicine residencies because they are uncertain what they want to do in the future, (2) more income to help individuals pay off their loans, and (3) the training of family physicians works well in the hospital setting. So, half full, or half empty?

To see this article online, please go to: http://jabfm.org/content/ 31/5/667.full.

\section{References}

1. Chang L, Wanner KJ, Kovalsky D, Smith KL, Rhodes KV. "It's really overwhelming": patient perspectives on care coordination. J Am Board Fam Med 2018;31:682-690.

2. Blasi PR, Cromp D, McDonald S, et al. Approaches to behavioral health integration at high performing primary care practices. J Am Board Fam Med 2018; 31:691-701.

3. Beck A, Boggs JM, Alem A, et al. Large-scale implementation of collaborative care management for de- pression and diabetes and/or cardiovascular disease. J Am Board Fam Med 2018;31:702-711.

4. Rossom RC, Solberg LI, Magnan S, et al. Impact of a national collaborative care initiative for patients with depression and diabetes or cardiovascular disease. Gen Hop Psychiatry 2017;44:77-85.

5. Jetelina KK, Woodson TT, Gunn R, et al. Evaluation of an electronic health record (EHR) tool for integrated behavioral health in primary care. J Am Board Fam Med 2018;31:712-723.

6. Hirschtritt ME, Kline-Simon AH, Kroenke K, Sterling SA. Depression screening rates and symptom severity by alcohol use among primary care adult patients. J Am Board Fam Med 2018;31:724-732.

7. Kondrad EC, Reed AJ, Simpson MJ, Nease DE. Lack of communication about medical marijuana use between doctors and their patients. J Am Board Fam Med 2018;31:805-808.

8. Sharma AE, Knox M, Peterson LE, Willard-Grace $\mathrm{R}$, Grumbach K, Potter MB. How is family medicine engaging patients at the practice-level?: a national sample of family physicians. J Am Board Fam Med 2018;31:733-742.

9. Bhuyan SS, Shiyanbola O, Deka P, et al. The role of gender in cost-related medication nonadherence among patients with diabetes. J Am Board Fam Med 2018;31:743-751.

10. Schoenthaler A, Rosenthal DM, Butler M, Jacobowitz L. Medication adherence improvement similar for shared decision-making preference or longer patient-provider relationship. J Am Board Fam Med 2018;31:752-760.

11. Hanba C, Hanba D. Opioid and drug prevalence in top 40's music: a 30 year review. J Am Board Fam Med 2018;31:761-767.

12. Myrick TG, Sandri KJ. Epidural analgesia and any vaginal laceration. J Am Board Fam Med 2018;31: 768-773.

13. Brown HW, Guan W, Schmuhl NB, Smith PD, Whitehead WE, Rogers RG. If we don't ask, they won't tell: screening for urinary and fecal incontinence by primary care providers. J Am Board Fam Med 2018;31:774-782.

14. Harrison EG, Keating JL, Morgan P. Novel exercises for restless legs syndrome: a randomized, controlled trial. J Am Board Fam Med 2018;31:783-794.

15. Yoon AP, Mathews AL, Huetteman HE, Michelotti $\mathrm{BF}$, Chung KC. Improving effective magnetic resonance imaging (MRI) application in soft tissue wrist injury. J Am Board Fam Med 2018;31:795-804.

16. Crawford P, Crawford AJ. Edema from taking cinnamon for treatment of diabetes: Similar biochemistry and pathophysiology to thiazolidinedione medications. J Am Board Fam Med 2018;31:809-811.

17. Mainous AG, Carek PJ, Lynch K, et al. Effectiveness of clinical decision support based intervention in the 
improvement of care for adult sickle cell disease patients in primary care. J Am Board Fam Med 2018;31:812-816.

18. Kulkami AK, Manek MB. Interruption and reversal of direct oral anticoagulants in preprocedural and acute settings. J Am Board Fam Med 2018;31:817827.
19. Kamerow DB, Wingrove P, Petterson S, Peterson L, Bazemore A. Characteristics of young family physician hospitalists. J Am Board Fam Med 2018;31: 680-681.

20. Jones KC, Whatley MM. Hospitalists: a growing part of the primary care workforce. AAMC Analysis in Brief 2016;16:1-2. 